\title{
Osmolarity and spectrophotometric property of brilliant blue green define the degree of toxicity on retinal pigment epithelial cells exposed to surgical endoilluminator
}

\author{
This article was published in the following Dove Press journal: \\ Clinical Ophthalmology \\ 16 August 2016 \\ Number of times this article has been viewed
}

\author{
Sankarathi Balaiya \\ Kumar Sambhav \\ William B Cook \\ Kakarla V Chalam \\ Department of Ophthalmology, \\ University of Florida College of \\ Medicine, Jacksonville, FL, USA
}

Correspondence: Kakarla V Chalam Department of Ophthalmology, University of Florida College of Medicine, 580, W, 8th Street, Tower-2, Jacksonville, FL 32209, USA

$\mathrm{Tel}+$ I 904244936 I

Fax + I 904244 939।

Email kvchalam@aol.com
Objective: To evaluate the effect of varying concentrations of brilliant blue green (BBG) and their different biochemical characteristics on retinal pigment epithelial (RPE) cells under xenon light source illumination at varying distances to identify safe parameters for intraoperative use.

Methods: Human retinal RPE cells (ARPE-19) were exposed to two concentrations ( 0.25 and $0.50 \mathrm{mg} / \mathrm{mL}$ ) of BBG and illuminated with a xenon surgical illuminator at varying distances (10 and $25 \mathrm{~mm}$ ), intensity levels, and time intervals (1, 5, and 15 minutes). Additionally, the effect of osmolarity was examined by diluting BBG in different concentrations of glucose. Cytotoxicity of BBG and osmolarity effects on cell viability were evaluated using a WST-1 assay. Light absorption and emission characteristic of BBG in different solvents were measured using a plate reader at different wavelengths. Lastly, the activity of caspase- 3 was also studied.

Results: Cell viability of ARPE-19 cells was $77.4 \% \pm 12.7 \%, 78.7 \% \pm 17.0 \%$, and $65.0 \% \pm 19.7 \%$ at 1,5 , and 15 minutes to exposure of high illumination xenon light at $10 \mathrm{~mm}(P<0.05)$ compared to controls. At both distances of illumination (10 and $25 \mathrm{~mm}$ ), similar cell viabilities were seen between 1 and 5 minutes of exposure. However, there was a decline in viability when the illumination was carried out to 15 minutes in all groups $(P<0.05)$. There was no significant reduction in cell viability in presence or absence of xenon light in different osmolar solutions concentrations of glucose $(P>0.05)$. Maximal light absorption of BBG was noted between 540 and $680 \mathrm{~nm}$. Activated caspase-3 level was not significant in both the concentrations of $\operatorname{BBG}(P>0.05)$.

Conclusion: Our findings suggest that BBG at $0.25 \mathrm{mg} / \mathrm{mL}$ during vitreoretinal surgery is safe and not toxic to RPE cells up to 5 minutes under focal high illumination $(10 \mathrm{~mm})$ and up to 15 minutes under medium diffuse illumination $(25 \mathrm{~mm}$ ). BBG was safe to be mixed with isotonic glucose solution at the concentration range of $2.5 \%-10 \%$, regardless of the illumination status. Keywords: brilliant blue green dye, endoilluminator, vitrectomy, human retinal RPE cells, internal limiting membrane peel

\section{Background}

Internal limiting membrane (ILM) peeling improves vitreoretinal surgical outcomes in idiopathic macular hole, epiretinal membrane, and recalcitrant diabetic macular edema, ${ }^{1,2}$ ILM, a thin transparent structure, is tough to visualize during vitrectomy. Complimentary staining with vital dyes, such as indocyanine green (ICG), improves its visualization and facilitates its safe and easy removal. However, there are established 
adverse events, such as visual field changes and retinal pigment epithelial (RPE) toxicity, after ICG-assisted peeling of the ILM..$^{3-5}$ Brilliant blue green (BBG), among several other dyes, has revealed a similar affinity to stain ILM with minimal toxicity. 6,7

Light used during vitrectomy (light pipe) can induce decay of vital dyes and enhance retinal injury. This retinal phototoxicity occurs because of the absorption of photons and is determined by the duration of application, power and emission spectrum, of endoillumination along with the distance of the light pipe from the retina. ${ }^{8,9}$ In addition, varying osmolarities of dye solutions were also shown to cause retinal insult. ${ }^{10}$ The biochemical and spectrophotometric effect of BBG (in different concentration of solvents) and the result of spectral overlap of xenon endoilluminator used in chromovitrectomy are limited. ${ }^{11}$

In this study, we evaluated the effect of varying concentrations of BBG with different physical characteristics (osmolarity and spectrophotometry) on RPE cells with xenon light source illumination at varying distances to obtain safe parameters of dye concentration and level of endoillumination during vitrectomy.

\section{Methods}

\section{Cell culture}

Human RPE cells (ARPE-19; American Type Culture Collection, Manassas, VA, USA) were established under customary culture conditions in the Dulbecco's Modified Eagle's Medium/F12 supplemented with $100 \mathrm{U} / \mathrm{mL}$ of penicillin, $100 \mathrm{mg} / \mathrm{mL}$ of streptomycin (Thermo Fisher Scientific, Waltham, MA, USA) and 10\% fetal bovine serum (Invitrogen Corporation). The cells were cultured in $75 \mathrm{~cm}^{2}$ filter-capped flasks $\left(95 \%\right.$ air and $5 \% \mathrm{CO}_{2}$ at $37^{\circ} \mathrm{C}$ of incubator conditions).

\section{Preparation of BBG and application of endoillumination light}

BBG (Sigma-Aldrich Co., St Louis, MO, USA) was mixed in the Hank's balanced saline solution (HBSS, Gibco BRL, Thermo Fisher Scientific) to get the concentrations of 0.25 and $0.5 \mathrm{mg} / \mathrm{mL}$ (designated for intraocular use). Xenon endoilluminator (light pipe) was used as light source (Welch Allyn, Skaneateles Falls, NY, USA). Culture dishes were protected from light using aluminum foil before exposure BBG, and its application on cells was also carried out in dark for 1,5 , and 15 minutes at the two different dye concentrations (each well/dish individually illuminated). Endoillumination light source (Synergetics, Inc., O’Fallon, MO, USA) was kept at a distance of 10 and $25 \mathrm{~mm}$ from the dish providing uniform illumination. The distance between the light sources and the dish was chosen based on its working distance during vitrectomy. Schematic and setup of experiments are shown in Figure 1A-E. Cells were washed thrice with HBSS after the exposure and/or illumination. Three experiments (with three series) at each time point were performed for each exposure. Experiments with only light illumination (with no BBG) served as controls.

\section{Standardization of light intensity}

Intensity of light was assessed using light meter with a range of 0-2,000 Foot candle (Fc; Extech Instruments Corporation Waltham, MA, USA). Medium and high illumination based on the fixed settings on the surgical system was taken as baseline for illumination. The illumination level at medium and high intensity at the source was the 1,000 and 2,000 Fc, respectively. Intensity of light at surface of the cells varied with the distance of light pipe used $(2,000$ and $1,750 \mathrm{Fc}$ at the distances of 10 and $25 \mathrm{~mm}$, respectively, for high illumination and 900 and $850 \mathrm{Fc}$ at the distance of 10 and $25 \mathrm{~mm}$, respectively, for medium illumination).

\section{Cytotoxicity assay}

Ten thousand cells per well were seeded in culture plates (24-well) and maintained to reach at least $60 \%-80 \%$ confluence in 48-72 hours before exposure to BBG. After treatment with BBG and xenon light exposure, cells were washed thrice with $0.5 \mathrm{~mL}$ of HBSS followed by incubation at $37^{\circ} \mathrm{C}$ with WST-1. Cell viability (after illumination) was evaluated using a WST-1 (4-[3-(4 iodophenyl)-2-(4-nitrophenyl)-2H5-tetrazolium]-1.3-benzene disulfonate), a colorimetric assay (Hoffman-La Roche Ltd., Basel, Switzerland). It assesses enzymatic breakdown of tetrazolium salts to formazan by mitochondria of viable cells. After 2 hours of incubation, the absorbance was read using microplate reader (BioTek Synergy HT, Winooski, VT, USA) at $440 \mathrm{~nm}(630 \mathrm{~nm}$ of reference wavelength). Results were presented as percentage of cell viability (normalized against control illumination).

\section{Evaluating osmolarity effect on cytotoxicity}

Three different concentrations of glucose $(2.5 \%, 5 \%$, and $10 \%$ ) were diluted in the presence and absence of $0.50 \mathrm{mg} / \mathrm{mL}$ of BBG using HBSS. Each solution was mixed to make a homogenous clear solution without any clumps. Each homogenous solution was checked to maintain a uniform $\mathrm{pH}$. Each concentration represented a different osmolar solution. 


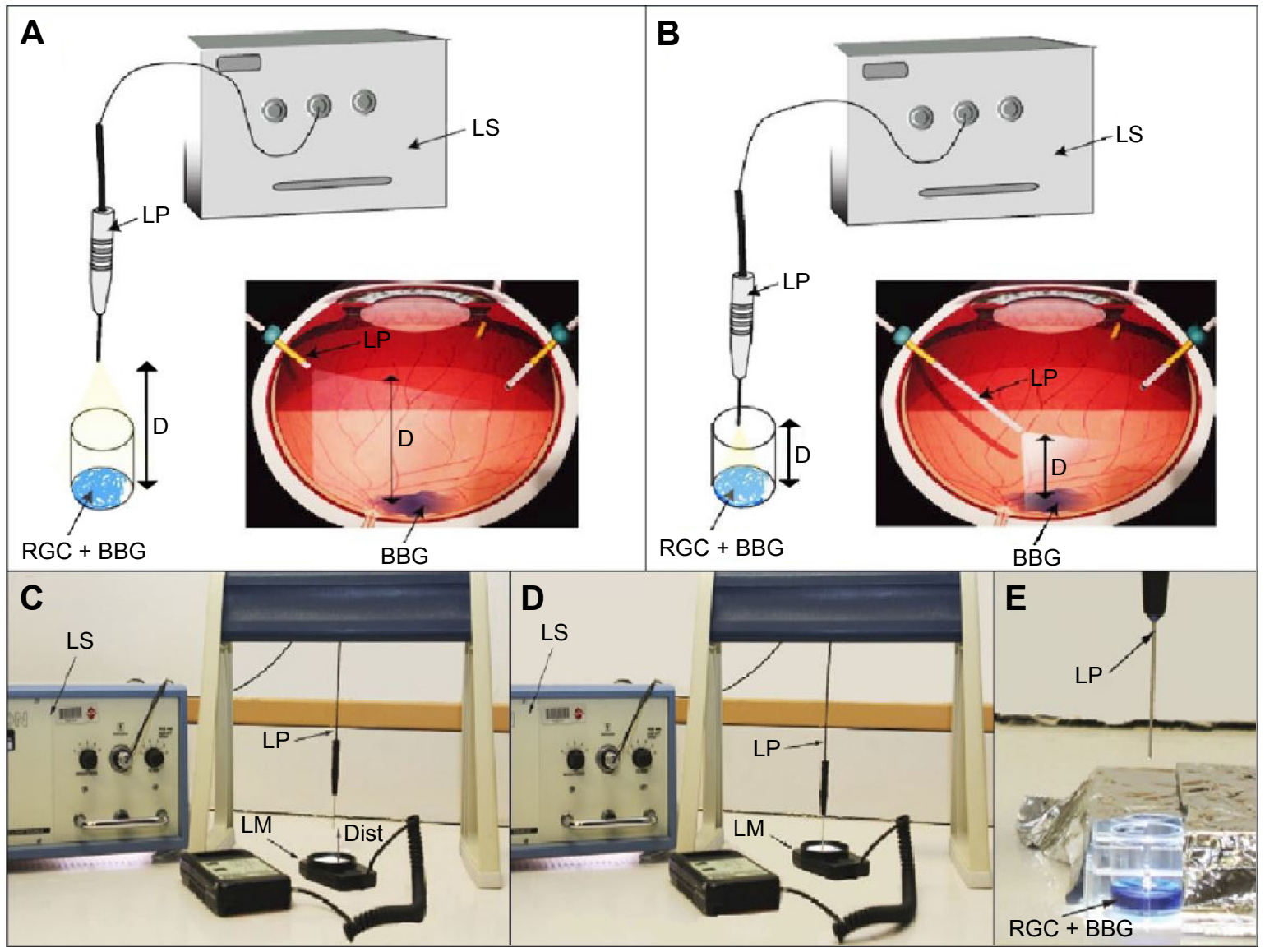

Figure I Schematic representation explains the intraocular exposure of BBG in the surgery as well as the cell culture setup.

Notes: (A) Exposure to BBG in presence of focal light illumination and (B) exposure to BBG in presence of bullet light illumination. Experimental setup illustrates evaluating xenon light illumination at a distance and source with the light meter (C and $\mathbf{D})$ and exposure to xenon illumination in presence of BBG in the experimental cell culture (E). Abbreviations: BBG, brilliant blue green; LM, light meter; LP, light probe; LS, light source; RGC, retinal ganglion cells.

Ten thousand cells per well were seeded in 96-well culture plates and maintained to reach $60 \%-80 \%$ confluence (48 hours) prior to the exposure of BBG at $0.5 \mathrm{mg} / \mathrm{mL}$ in different concentrations of $2.5 \%, 5 \%$, and $10 \%$ glucose in HBSS. After treatment, the effect of BBG in glucose was evaluated both with and without exposure to xenon light (high intensity, $10 \mathrm{~mm}$ working distance) using WST-1 assay as described earlier. Cells that were exposed only to HBSS in the presence of xenon light served as controls. Further, to evaluate whether BBG plays any role in causing cytotoxicity, we observed the cytotoxicity of BBG in HBSS in the presence and absence of xenon illumination. Results were normalized against controls and reported as percentage of viable cells.

\section{Emission spectrum and light absorption properties of BBG}

We selected 0.25 and $0.50 \mathrm{mg} / \mathrm{mL}$ to examine the light absorbance characteristics of BBG. However, with appropriate selective retinal application of vital dyes, little or no diffusion occurs in the vitreous cavity, implying that concentrations $>0.50 \mathrm{mg} / \mathrm{mL}$ may not be encountered in the surgical setting. Absorption of BBG in HBSS at both concentrations was measured with and without exposure to xenon light for 10 minutes. Light absorbance was also measured in different solvents with 0.25 and $0.50 \mathrm{mg} / \mathrm{mL}$ of BBG in HBSS or BSS and $0.50 \mathrm{mg} / \mathrm{mL}$ in water or glucose $(2.5 \%, 5 \%$, and $10 \%$ ) immediately after preparation using the plate reader (BioTek Synergy HT) between wavelength ranges from 260 to $900 \mathrm{~nm}$. All measurements were repeated twice, and the samples were analyzed within 30 minutes. To analyze and compare the absorbance spectra, absorbance data were collected and curves were constructed.

\section{Intracellular analysis of caspase- 3 activity}

We evaluated whether cytotoxicity occurred through activation of caspase- 3 , a death protease that acts as a key mediator in the induction of apoptosis, using In-Cell 
ELISA assay (Thermo Fisher Scientific). We seeded $10 \times 10^{3}$ cells/well in 24-well microtiter plates and allowed to attach for 48 hours. Cells were treated with 0.25 and $0.50 \mathrm{mg} / \mathrm{mL}$ concentrations of BBG and exposed to xenon light illumination at a $10 \mathrm{~mm}$ distance for 10 minutes. Cells without any treatment but which were exposed to light served as controls. Activation of caspase-3 was evaluated as per manufacturer's instructions. In brief, after treatment cells were fixed using 4\% paraformaldehyde and permeabilized for 15 minutes using $1 \times$ surfact-amps X-100. Cell permeabilization was quenched using $30 \% \mathrm{H}_{2} \mathrm{O}_{2}$ followed by addition of blocking buffer for 30 minutes. Cells were incubated with caspase- 3 at 1:500 at $4{ }^{\circ} \mathrm{C}$ overnight. After washing, they were incubated with anti-rabbit horseradish peroxidase conjugate for 30 minutes at room temperature followed by the addition of TMB substrate. Cleaved caspase- 3 was assessed by measuring the absorbance at $450 \mathrm{~nm}$ using the microplate reader. The results were compared against internal control alpha-tubulin and the intensity of signal presented in absorbance units (AU). The ratio of caspase-3 and cell number was calculated, normalized, and expressed in $\mathrm{mg} / \mathrm{dL}$. Experiments were repeated for concordance.

\section{Statistical analysis}

Results were expressed as mean \pm standard deviation. The data were analyzed using the GraphPad Instat3 software (GraphPad Software, Inc., La Jolla, CA, USA). Statistical significance of differences between groups was compared using the Student's $t$-test (unpaired or paired) or two-way analysis of variance. Statistical significance was accepted for $P$-values $<0.05$ or 0.01 .

A

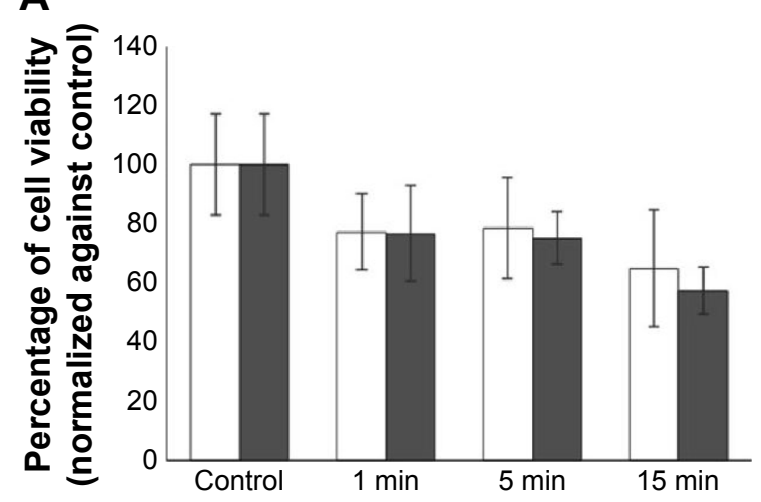

\section{Results \\ Cytotoxic effects of BBG with endoillumination}

The spectrophotometric absorbance measurement of dyeexposed cells with illumination was done to determine the percent of viability change (normal conditions, represented $100 \%$ viability).

\section{At $10 \mathrm{~mm}$ distance of high xenon illumination}

At 0.25 and $0.5 \mathrm{mg} / \mathrm{mL}$ concentrations, ARPE-19 cells demonstrated gradual increase in cytotoxicity with increase in duration of exposure. At $0.25 \mathrm{mg} / \mathrm{mL}$ concentration, cell viabilities after 1,5 , and 15 minutes of exposure were $77.4 \% \pm 12.7 \%, 78.7 \% \pm 17.0 \%$, and $65.0 \% \pm 19.7 \%$ of control, respectively. At $0.5 \mathrm{mg} / \mathrm{mL}$ concentration, cell viabilities after the same time points were $76.9 \% \pm 16.1 \%, 75.3 \% \pm 8.7 \%$, and $57.5 \% \pm 8.0 \%$ of control ( $P<0.05$; Figure $2 \mathrm{~A})$.

\section{At $10 \mathrm{~mm}$ distance of medium xenon illumination}

At $0.25 \mathrm{mg} / \mathrm{mL}$ concentration, cell viabilities after 1, 5, and 15 minutes of exposure were $90.9 \% \pm 15.2 \%, 70.8 \% \pm 6.6 \%$, and $67.6 \% \pm 12.0 \%$ of control, respectively. At $0.5 \mathrm{mg} / \mathrm{mL}$ concentration, cell viabilities after the same time points were $89.5 \% \pm 17.6 \%, 78.1 \% \pm 16.9 \%$, and $63.7 \% \pm 1.7 \%$ of control $(P<0.05$; Figure 2B).

\section{At $25 \mathrm{~mm}$ distance, high xenon illumination}

At $25 \mathrm{~mm}$ from the xenon light source, cell viabilities at $0.25 \mathrm{mg} / \mathrm{mL}$ BBG concentration after 1,5 , and 15 minutes

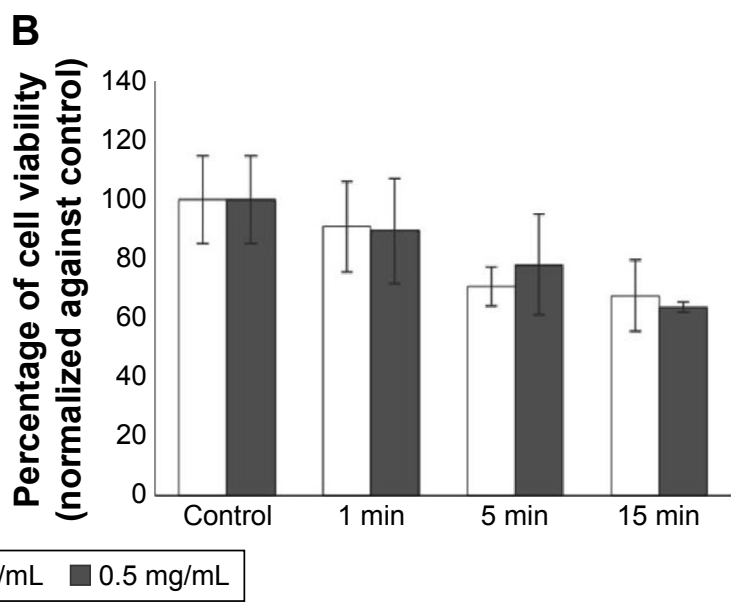

Figure 2 Showing the cytotoxic effect of brilliant blue green at $10 \mathrm{~mm}$ xenon distance illumination on retinal pigment epithelial cells using WST-I assay at high (A) and medium illumination (B).

Notes: $X$-axis represents the time-dependent exposure in minutes, $y$-axis represents number of viable cells expressed as percentage of control ( $n=3$ ). 


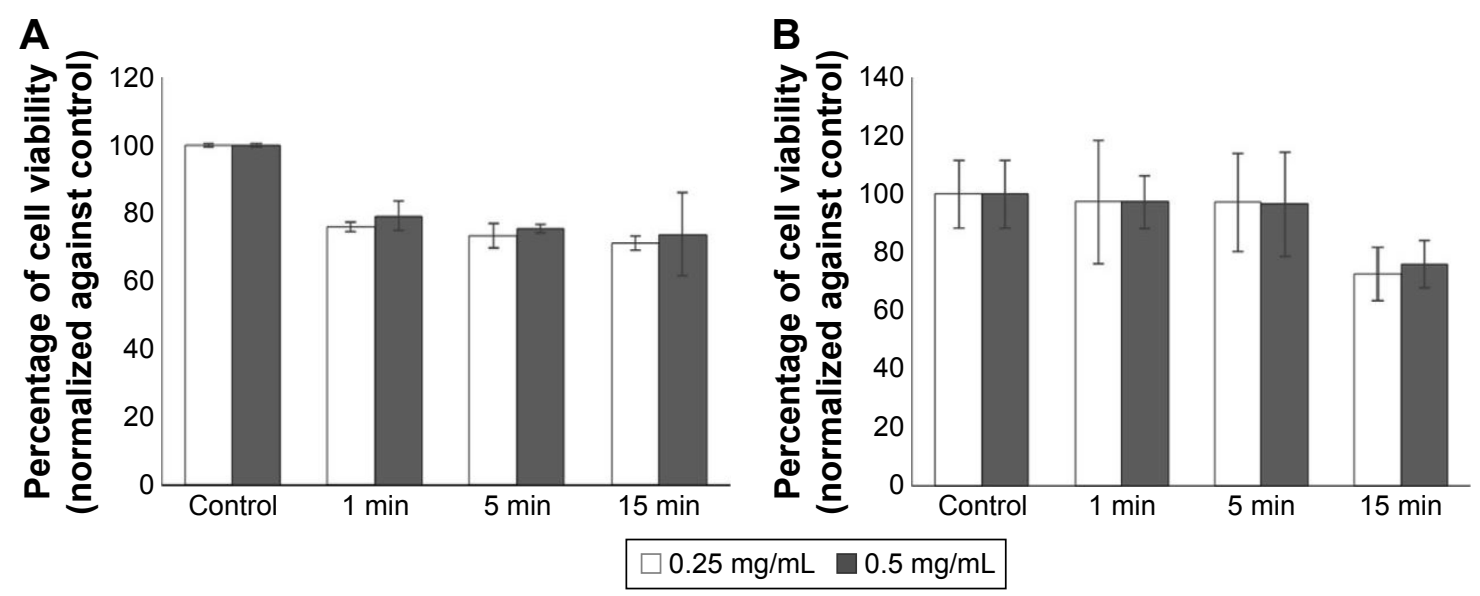

Figure 3 Evaluating the cytotoxic effect of brilliant blue green at $25 \mathrm{~mm}$ xenon distance illumination on retinal pigment epithelial cells using WST-I assay at high (A) and medium illumination (B).

Notes: $\mathrm{X}$-axis represents the time-dependent exposure in minutes, $\mathrm{y}$-axis represents number of viable cells expressed as percentage of control ( $\mathrm{n}=3$ ).

exposure were $76.0 \% \pm 1.4 \%, 73.4 \% \pm 3.6 \%$, and $71.2 \% \pm 2.1 \%$ of control, respectively. At $0.5 \mathrm{mg} / \mathrm{mL}$ concentration, cell viabilities after the same time points were $79.2 \% \pm 4.2 \%$, $75.5 \% \pm 1.2 \%$, and $73.7 \% \pm 12.2 \%$ of control $(P<0.05$; Figure 3A).

\section{At $25 \mathrm{~mm}$ distance, medium illumination}

For this treatment, cell viabilities at $0.25 \mathrm{mg} / \mathrm{mL} B B G$ concentration after 1, 5, and 15 minutes exposure were $97.2 \% \pm 21.1 \%, 97.1 \% \pm 16.7 \%$, and $72.6 \% \pm 9.2 \%$ of control, respectively. At $0.5 \mathrm{mg} / \mathrm{mL}$ concentration, cell viabilities after the same time points were $97.2 \% \pm 8.9 \%, 96.5 \% \pm 17.8 \%$, and $76.0 \% \pm 8.2 \%$ of control $(P<0.05$; Figure $3 \mathrm{~B})$.

\section{Cytotoxicity in different osmolar solutions}

All the solutions with varying concentrations of glucose had a constant neutral $\mathrm{pH}$ of 7 . The spectrophotometric absorbance measurement of HBSS-exposed cells was done as control to determine the percent of viability change (Figure 4).

\section{With BBG}

At $0.05 \%$ of $\mathrm{BBG}$, cell viability at $2.5 \%, 5.0 \%$, and $10.0 \%$ of glucose solution in presence of xenon illumination was $93.04 \% \pm 4.26 \%, 103.0 \% \pm 3.1 \%$, and $98.0 \% \pm 4.7 \%$ of control, respectively. Cell viability at $2.5 \%, 5.0 \%$, and $10.0 \%$ of glucose solution in the absence of xenon illumination was $88.4 \% \pm 7.0 \%$, $84.0 \% \pm 10.3 \%$, and $89.1 \% \pm 5.5 \%$ of control, respectively. Though there was a reduction in cell viability in the different osmolar or glucose solutions in the absence of xenon illumination, the reduction was not significant ( $P>0.05$; Figure 4A). BBG that was dissolved in the absence of glucose (in HBSS) does not have any cytotoxicity in presence $(95.9 \% \pm 8.5 \%)$ and absence of xenon illumination (101.2\% $\pm 8.1 \%)$.
A

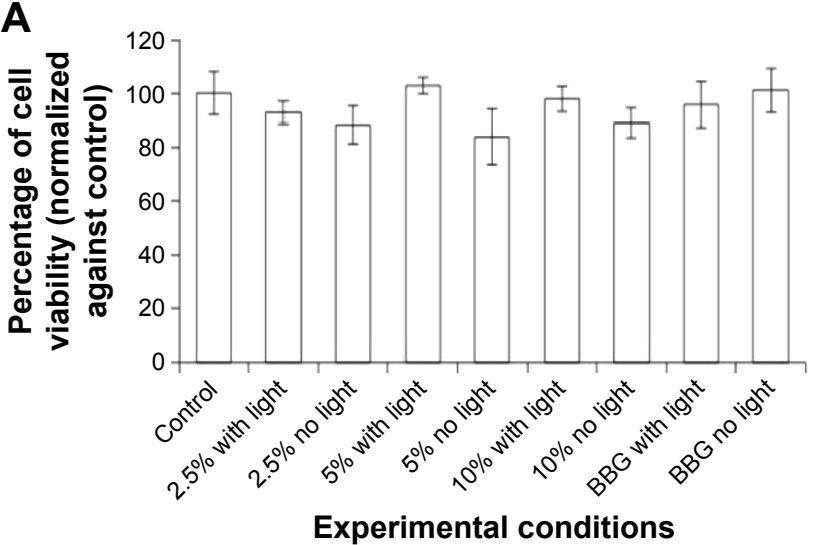

B

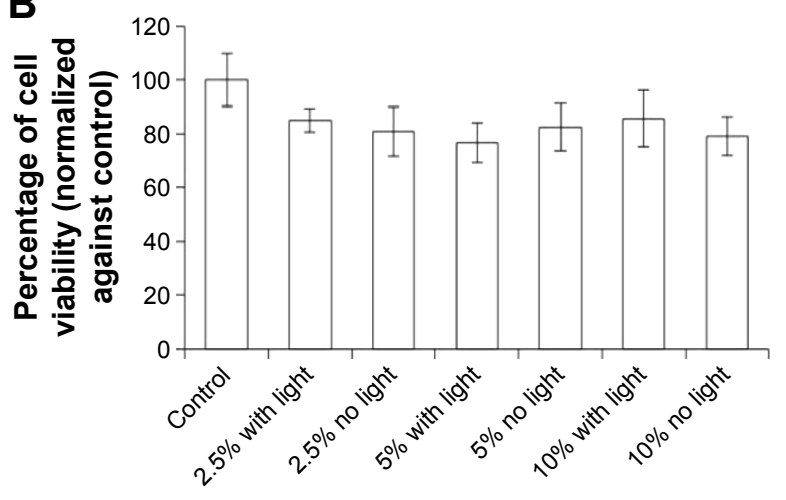

Experimental conditions

Figure 4 Evaluating the cytotoxic effect of different solvents using $0.05 \%$ of BBG (A) and without BBG (B) at 25 mm xenon distance illumination on retinal pigment epithelial cells using WST-I assay.

Notes: $\mathrm{X}$-axis represents the experimental conditions, $\mathrm{y}$-axis represents number of viable cells expressed as percentage of control $(\mathrm{n}=3)$.

Abbreviation: BBG, brilliant blue green. 


\section{Without BBG}

Cell viability at $2.5 \%, 5.0 \%$, and $10.0 \%$ of glucose solution in presence of xenon illumination was $85.0 \% \pm 4.3 \%$, $76.6 \% \pm 7.4 \%$, and $85.6 \% \pm 10.4 \%$ of control, respectively. Cell viability at $2.5 \%, 5.0 \%$, and $10.0 \%$ of glucose solution in the absence of xenon illumination was $80.8 \% \pm 9.1 \%$, $82.4 \% \pm 8.7 \%$, and $79.1 \% \pm 7.2 \%$ of control, respectively (Figure 4B).

\section{Light absorption properties and emission spectrum of BBG}

We evaluated the light absorption properties and emission spectrum of BBG between 260 and $900 \mathrm{~nm}$ in different solvents. All BBG solutions had similar double-peak curves. The first peak was noted at 260-280 nm and the second peak occurred between 540 and $680 \mathrm{~nm}$. Between peaks, each emission spectrum exhibited similar low absorbance values between 350 and $450 \mathrm{~nm}$. Beyond $720 \mathrm{~nm}$, no additional peaks were observed (Figure 5).

\section{HBSS and BSS}

The emission spectrum showed two distinct peaks. The first peak was noted at 260 and $280 \mathrm{~nm}$, and a broad peak between 540 and $680 \mathrm{~nm}$ (Figure 5A). We did not find any difference between the two concentrations of BBG except the closeness of the peak at $0.25 \mathrm{mg} / \mathrm{mL}$ of BBG (Figure $5 \mathrm{~B}$ ). Absorption spectrum of BBG was not altered after exposure to xenon light for 10 minutes in both the concentrations. In BSS, absorbance spectrum peaked at 260-280 nm and 540-680 nm for both concentrations of BBG. At $630,0.5 \mathrm{mg} / \mathrm{mL}$ had a higher peak than $0.25 \mathrm{mg} / \mathrm{mL} ; 0.5 \mathrm{mg} / \mathrm{mL}$. In addition, consistent high absorption was noted throughout the emission spectrum at this concentration (Figure 5C).

\section{Glucose solutions in HBSS and BSS}

Absorbance for all three varying concentrations of glucose $(2.5 \%, 5 \%$, and $10 \%)$ peaked at 260-280 and 540-680 nm (Figure 5D). The 2.5\% glucose solution displayed a lower absorbance spectrum compared with the 5.0\% and $10.0 \%$ solutions. In BSS, absorbance spectrum peaked at 260-280 and 540-680 nm for all solutions. All solutions displayed similar absorbance values throughout the emission spectrum (Figure 5E).

\section{Glucose solutions in $\mathrm{H}_{2} \mathrm{O}$}

Absorbance spectrum of BBG dissolved in varying concentrations of glucose in water also showed similar pattern like BSS and HBSS. Absorbance spectrum peaked at 260-280 and
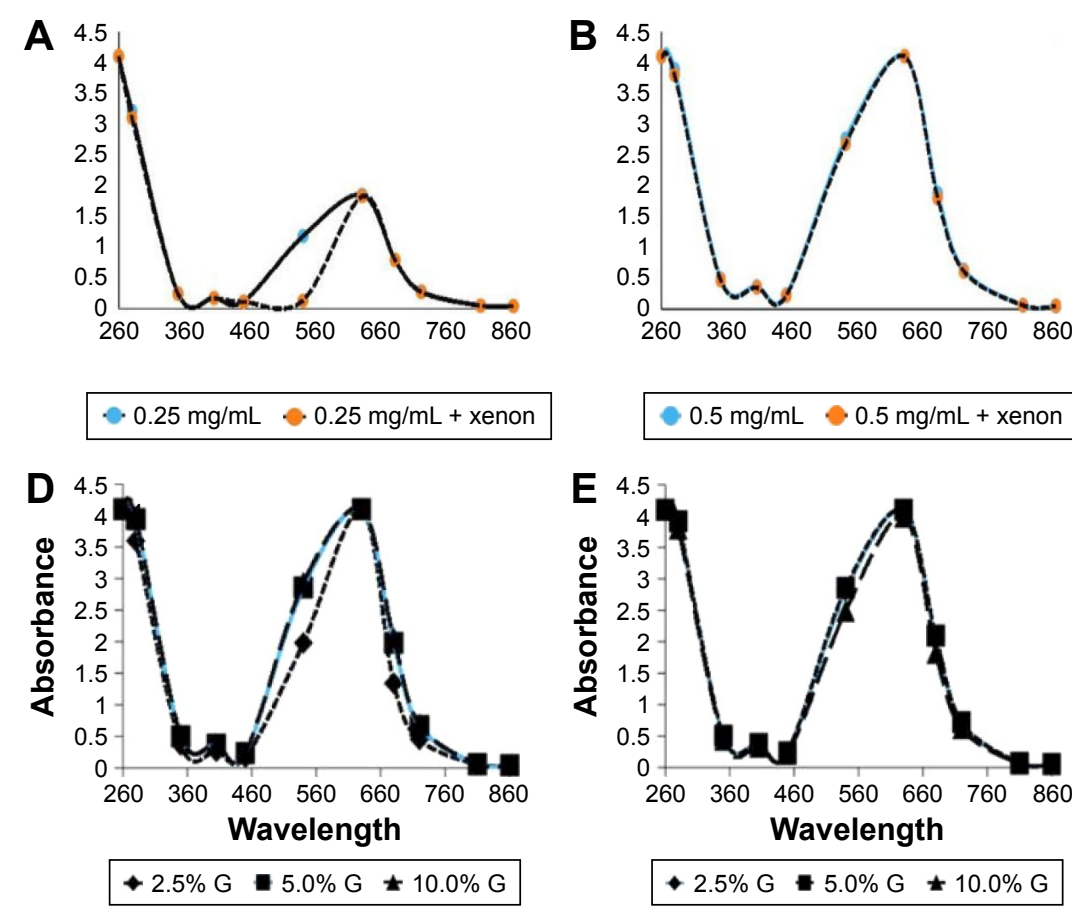

Figure 5 Absorption spectrum of BBG in different solvents.

Notes: (A) $0.25 \mathrm{mg} / \mathrm{mL}$ of BBG with or without exposed to xenon for 10 minutes; (B) $0.5 \mathrm{mg} / \mathrm{mL}$ of BBG with or without exposed to xenon for 10 minutes; (C) BBG in balanced salt solution; (D) BBG in different concentrations of glucose in HBSS; (E) BBG in different concentrations of glucose in balanced salt solution; and (F) BBG in different concentrations of glucose in $\mathrm{H}_{2} \mathrm{O}$.

Abbreviations: BBG, brilliant blue green; HBSS, Hank's balanced saline solution.

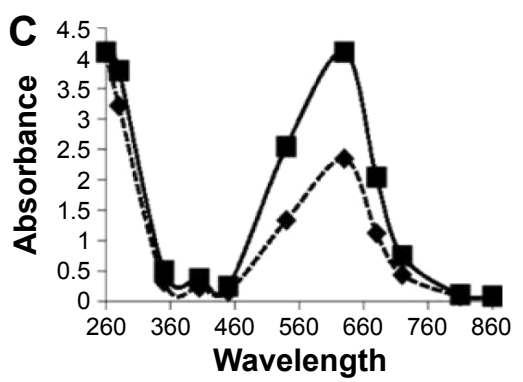

$\leftarrow 0.25 \mathrm{mg} / \mathrm{mL}=0.5 \mathrm{mg} / \mathrm{mL}$

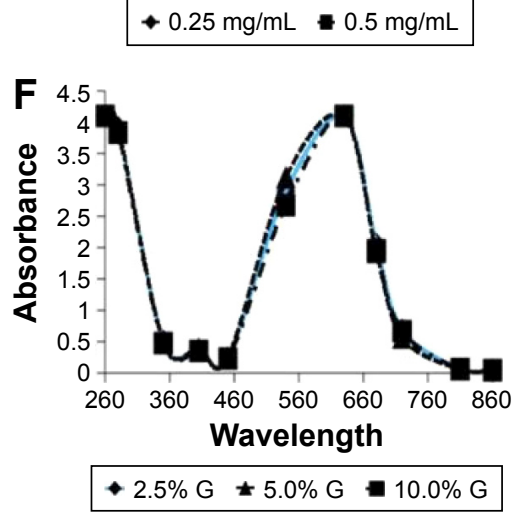

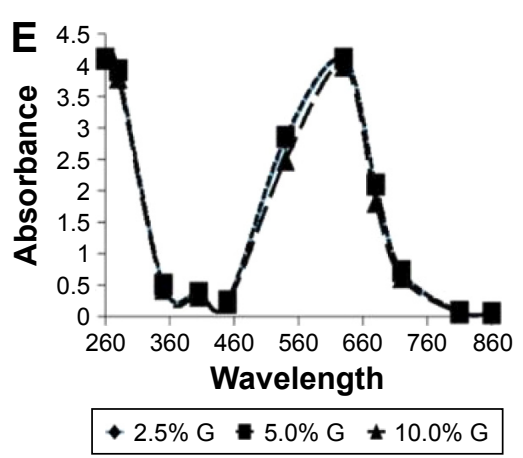


540-680 nm for each solution (Figure 5F). We did not find any difference in spectral values between the varying concentrations of glucose that was dissolved in medium.

\section{Activated caspase-3/apoptosis evaluation}

At high illumination, in comparison to control cells ( $0.272 \pm 0.001 \mathrm{AU}), 0.25 \mathrm{mg} / \mathrm{mL}$ of BBG showed $0.227 \pm 0.002$ AU of caspase- 3 and $0.5 \mathrm{mg} / \mathrm{mL}$ of BBG showed $0.241 \pm 0.029$ AU. Similar observation was noted at medium illumination of xenon light after 10 minutes of exposure. At $0.25 \mathrm{mg} / \mathrm{mL}$ BBG, medium illumination showed $0.208 \pm 0.005 \mathrm{AU}$ and $0.05 \%$ showed $0.22 \pm 0.005$ AU compared to control cells $(0.24 \pm 0.007 \mathrm{AU})$. Reduced activation of caspase- 3 was observed in both the concentrations as well in two different illumination levels. The decreased activation of caspase-3 was not statistically significant $(P>0.05)$.

\section{Discussion}

The ILM plays a significant role in the pathogenesis of vitreomacular interface diseases. Successful surgical management of vitreoretinal interface diseases depends on peeling of the ILM and reliving tangential traction from the retina. ILM peeling also removes the scaffold for possible, recurrent ERM (Epiretinal membrane).

ILM peeling gained popularity after introduction of ICG as it enhanced visualization and removal of ILM. ${ }^{12}$ Vital dyes are commonly used to stain and peel the ILM. Staining ILM decreases the chances of mechanical trauma during its peel and thus improves surgical outcome. ${ }^{12}$ Studies have demonstrated toxic effects of vital dyes, especially ICG, on retinal cells. Furthermore, poor recovery of vision, postoperative visual field defects, and RPE atrophy have been ascribed to the use of ICG. ${ }^{13}$ Alternative dyes have been used to facilitate ILM staining having less toxicity. ${ }^{14}$ Among the numerous dyes tested, infracyanine G, BBG, and bromophenol blue show the highest affinity for ILM. ${ }^{14}$ Of those, BBG has shown similar affinity to stain the ILM as ICG with minimal toxicity. ${ }^{14}$

BBG was introduced for ILM staining about a decade ago for ILM peel during macular hole surgery. ${ }^{14}$ Animal studies of BBG have shown promising safety profile compared to ICG after subretinal and intravitreal injections. ${ }^{14}$ BBG use showed better final visual outcomes 6 months after surgery compared to ICG.

Despite better outcomes with the use of BBG, in vitro side effects of $B B G$ have been reported. BBG can persuade necrosis of ARPE-19 and retinal ganglion cells with $>5$ minutes of exposure. ${ }^{8}$
In addition, vital dyes can prompt photochemical retinal injury by increasing levels of free radicals, as an overlap of absorbance spectrum facilitates the absorbance light by the retina stained with dye, especially with the use of ICG. ${ }^{15}$ For other dyes (including BBG), a reduction in cell viability has been reported with the use of visible light endoilluminator. ${ }^{14}$

ARPE-19 were exposed to two concentrations of BBG $(0.25$ and $0.5 \mathrm{mg} / \mathrm{mL})$ and exposed to xenon endoilluminator for 1,5 , and 15 minutes. Illumination was positioned at varying distances (10 and $25 \mathrm{~mm}$ ) to simulate surgical distance of light pipe. We found that BBG at concentration of $0.25 \mathrm{mg} / \mathrm{mL}$ (clinically used) is safe and not toxic to ARPE-19 for 5 minutes with focal illumination $(10 \mathrm{~mm})$ and for 15 minutes under diffuse illumination $(25 \mathrm{~mm})$.

Our results showed that the cytotoxic effect of BBG is directly correlated to exposure time to xenon endoillumination. Regardless of the BBG concentrations or illumination distances, exposure time of 15 minutes induced more RPE cell death compared to shorter exposure period of 1 and 5 minutes. In addition, BBG toxicity is also inversely related to the intensity of the xenon illumination. For example, with 5 minutes exposure, focal $(10 \mathrm{~mm})$ maximum illumination resulted in cell viability of $78.7 \% \pm 17 \%$ and $75.3 \% \pm 8.7 \%$ at BBG concentration of 0.25 and $0.5 \mathrm{mg} / \mathrm{mL}$, respectively; while diffuse $(25 \mathrm{~mm})$ medium illumination led to cell viability of $97.1 \% \pm 16.7 \%$ and $96.5 \% \pm 17.8 \%$ at $B B G$ concentration of 0.25 and $0.5 \mathrm{mg} / \mathrm{mL}$, respectively. Our findings also suggest that the $25 \mathrm{~mm}$ diffuse illumination distance, which is commonly used in vitrectomy, provides a safety window of 15 minutes for 0.25 and $0.5 \mathrm{mg} / \mathrm{mL} \mathrm{BBG}$ (cell viability $72.6 \% \pm 9.2 \%, 76.0 \% \pm 8.2 \%$, respectively) before RPE phototoxicity is noted. On the other hand, the focal illumination can cause significant toxicity just with 5 minutes of exposure irrespective of the BBG concentration.

Another factor that would determine the retinal toxicity of vital dye is the solvent. ICG toxicity to the RPE is dependent on the dye concentration, the osmolarity of the solvent solutions, as well as on the lengths of dye exposure time and of the illumination time. ${ }^{16}$ In contrast, our data showed that $0.5 \mathrm{mg} / \mathrm{mL} \mathrm{BBG}$ dissolved in isotonic glucose solvent did not result in significant RPE cytotoxicity at any of the tested concentrations $(2.5 \%, 5 \%$, and $10 \%)$. These effects were also not influenced by the presence or absence of xenon illumination. Interestingly, Costa et al reported that significant toxicity was detected in vitro for ARPE-19 cells when they were exposed for 10 minutes in $0.5 \mathrm{mg} / \mathrm{mL}$ trypan blue mixed with glucose solutions of various concentrations $(2.5 \%, 5.0 \%, 10 \%, 20 \%, 40 \%$, and $50 \%)$ even 
in iso-osmolar range. ${ }^{17}$ The evidence seems to suggest that BBG may be safer to mix with glucose solution when used for chromovitrectomy compared to other dyes, but further investigation is warranted to confirm this.

Endoilluminators with wavelengths exposure of below $400 \mathrm{~nm}$ also causes photoreceptor damage, whereas $>400 \mathrm{~nm}$ light wavelength exposure induces phototoxic effects mainly in RPE cells. ${ }^{18}$ Xenon light has a peak wavelength of $450 \mathrm{~nm}$ (range 420-700 nm). ${ }^{9}$ Vital dyes are small chemical molecules that easily penetrate retina and produces phototoxic free radicals due to changes in emission spectrum after absorption of light. Our data support the earlier observation by showing high spectral peaks between 540 and $680 \mathrm{~nm}$ in the presence of BBG with or without xenon light for 10 minutes. BBG has absorption maxima at $595 \mathrm{~nm}$ (range 465-595 nm). ${ }^{19}$ This absorption of light and duration of use (10 minutes) did not shift the emission spectrum of light toward the retinal damage.

Changes in $\mathrm{pH}$ can produce change in c-wave and $\mathrm{b}$-wave on electroretinogram on cat eye retina. ${ }^{20} \mathrm{~A}$ reaction between light and acid-base disturbances occurs on the retina because photoreceptor light response may induce changes in $\mathrm{pH}$ through alterations in subretinal $\mathrm{K}^{+}$levels. ${ }^{9}$ In our study, to focus whether BBG or xenon light is causing RPE toxicity, we maintained the uniform $\mathrm{pH}$ during our experiments. We evaluated the RPE cytotoxicity in the presence of BBG and xenon by analyzing caspase-3 a death protease and a key mediator in inducing apoptosis. However, we did not find any apoptosis through caspase-3 pathway.

\section{Conclusion}

In conclusion, our findings suggest that in vitro cytotoxic effects of BBG on RPE cells directly correlated with the exposure time and inversely correlated with the intensity of the commonly used xenon endoillumination. We also found that BBG was safe to be mixed with isotonic glucose solution at the concentration range of $2.5 \%-10 \%$, regardless of the illumination status. Additionally, BBG at its clinically used concentration is safe to be used for 5 minutes under focal illumination and for 15 minutes under diffuse illumination.

\section{Disclosure}

The authors report no conflicts of interest in this work.

\section{References}

1. Rodrigues EB, Costa EF, Penha FM, et al. The use of vital dyes in ocular surgery. Survey Ophthalmol. 2009;54(5):576-617.
2. Cornish K, Lois N, Scott N, et al. Vitrectomy with internal limiting membrane (ILM) peeling versus vitrectomy with no peeling for idiopathic full-thickness macular hole (FTMH). Cochrane Database Syst Rev. 2013;(6):CD009306.

3. Balaiya S, Brar VS, Murthy RK, Chalam KV. Comparative in vitro safety analysis of dyes for chromovitrectomy indocyanine green, brilliant blue green, bromophenol blue, and infracyanine green. Retina. 2011; 31(6): 1128-1136.

4. Rodrigues EB, Penha FM, de Paula Fiod Costa E, et al. Ability of new vital dyes to stain intraocular membranes and tissues in ocular surgery. Am J Ophthalmol. 2010;149(2):265-277.

5. Naithani P, Vashisht, N, Khanduja S, Sinha S, Garg S. Brilliant blue $\mathrm{G}$-assisted peeling of the internal limiting membrane in macular hole surgery. Indian J Ophthalmol. 2011;59(2):158-160.

6. Awad D, Schrader I, Bartok M, Mohr A, Gabel D. Comparative toxicology of trypan blue, brilliant blue $\mathrm{G}$, and their combination together with polyethylene glycol on human pigment epithelial cells. Invest Ophthalmol Vis Sci. 2011;52(7):4085-4090.

7. Ooi YL, Khang TF, Naidu M, Fong KC. The structural effect of intravitreal brilliant blue $\mathrm{G}$ and indocyanine green in rats eyes. Eye (Lond). 2013; 27(3):425-431.

8. Balaiya S, Koushan K, McLauchlan T, Chalam KV. Assessment of the effect of distance and duration of illumination on retinal pigment epithelial cells exposed to varying doses of brilliant blue green. $J$ Ocul Pharmacol Ther. 2014;30(8):625-633.

9. Costa Ede P, Rodrigues EB, Farah MD, et al. Vital dyes and light sources for chromovitrectomy: comparative assessment of osmolarity, $\mathrm{pH}$, and spectrophotometry. Invest Ophthalmol Vis Sci. 2009;50(1):385-391.

10. Shirao Y, Steinberg RH. Mechanisms of effects of small hyperosmotic gradients on the chick RPE. Invest Ophthalmol Vis Sci. 1987;28(12): 2015-2025.

11. Henrich PB, Valmaggia C, Lang C, Cattin PC. The price for reduced light toxicity: do endoilluminator spectral filters decrease color contrast during Brilliant Blue G-assisted chromovitrectomy? Graefes Arch Clin Exp Ophthalmol. 2014;252(3):367-374.

12. Da Mata AP, Burk SE, Riemann CD, et al. Indocyanine green-assisted peeling of the retinal internal limiting membrane during vitrectomy surgery for macular hole repair. Ophthalmology. 2001;108(7):1187-1192.

13. Gandorfer A, Haritoglou C, Kampik A. Toxicity of indocyanine green in vitreoretinal surgery. Dev Ophthalmol. 2008;42:69-81.

14. Hernández F, Alpizar-Alvarez N, Wu L. Chromovitrectomy: an update. J Ophthalmic Vis Res. 2014;9(2):251-259.

15. Yonekawa Y, Abbey AM, Shah AR, Thomas BJ, Capone A Jr. Endoilluminator phototoxic maculopathy associated with combined ICGassisted epiretinal membrane and internal limiting membrane peeling. Clin Ophthalmol. 2014;8:2501-2506.

16. Kernt M, Hirneiss C, Wolf A, et al. Indocyanine green increases lightinduced oxidative stress, senescence, and matrix metalloproteinases 1 and 3 in human RPE cells. Acta Ophthalmol. 2012;90(6):571-579.

17. Costa E, Barros N, Coppini L, et al. Effects of light exposure, pH, osmolarity, and solvent on the retinal pigment epithelial toxicity of vital dyes. Am J Ophthalmol. 2013;155(4):705-712.

18. Gorgels TG, van Norren D. Ultraviolet and green light cause different types of damage in rat retina. Invest Ophthalmol Vis Sci. 1995;36(5): 851-863.

19. Takayama K, Sato T, Karasawa Y, Sato S, Ito M, Takeuchi M. Phototoxicity of indocyanine green and brilliant blue $\mathrm{G}$ under continuous fluorescent illumination on cultured human retinal pigment epithelial cells. Invest Ophthalmol Vis Sci. 2012;53(11):7389-7394.

20. Niemeyer G. Acid-base balance affects electroretinogram b- and c-wave differentially in the perfused cat eye. Doc Ophthalmol. 1986;63(2): 113-120. 
Clinical Ophthalmology

\section{Publish your work in this journal}

Clinical Ophthalmology is an international, peer-reviewed journal covering all subspecialties within ophthalmology. Key topics include: Optometry; Visual science; Pharmacology and drug therapy in eye diseases; Basic Sciences; Primary and Secondary eye care; Patien Safety and Quality of Care Improvements. This journal is indexed on

Submit your manuscript here: http://www.dovepress.com/clinical-ophthalmology-journal

PubMed Central and CAS, and is the official journal of The Society of Clinical Ophthalmology (SCO). The manuscript management system is completely online and includes a very quick and fair peer-review system, which is all easy to use. Visit http://www.dovepress.com/ testimonials.php to read real quotes from published authors. 